Asian Spine Journal

Vol. 1, No. 1, pp 8 11, 2007

\title{
Serum Levels of TGF-ß1, TIMP-1 and TIMP-2 in Patients with Lumbar Spinal Stenosis and Disc Herniation
}

\author{
Hyung-Jun Kim, Jong-Beom Park*, Ho-Yeon Won, Han Chang ${ }^{\dagger}$ \\ *Department of Orthopedic Surgery, The Catholic University of Korea School of Medicine, Seoul, Korea \\ ${ }^{+}$Spine Center, Department of Orthopedic Surgery, Sun General Hospital, Daejeon, Korea
}

Study Design: The serum levels of transforming growth factor-beta 1 (TGF- $\beta 1$ ), tissue inhibitor of matrix metalloproteinase-1 (TIMP-1) and TIMP-2 were measured by enzyme-linked immunosorbent assay.

Purpose: To compare the serum levels of TGF- $\beta 1$, TIMP-1 and TIMP-2 between patients with lumbar spinal stenosis and disc herniation.

Overview of Literature: It has been reported that increased concentrations of TGF- $\beta 1$, TIMP- 1 and TIMP-2 in the ligamentum flavum might be a possible pathogenesis for ligamentum flavum hypertrophy in spinal stenosis. However, it is not determined whether this phenomenon in spinal stenosis is a local or systemic problem.

Methods: The concentrations of TGF- $\beta 1$, TIMP -1 and TIMP- 2 were quantitatively analyzed by ELISA in the ligamentum flavum and serum of patients with lumbar spinal stenosis $(n=16)$ and disc herniation $(n=16)$. The thickness of ligamentum flavum was measured on axial T1-weigted magnetic resonance image. The biochemical and radiological results were compared for the two conditions.

Results: The thickness of the ligamentum flavum was larger in patients with spinal stenosis compared with that with disc herniation ( $\mathrm{p}=0.001$ ). The mean concentrations of TGF $-\beta 1$, TIMP -1 , and TIMP -2 in the ligamentum flavum were significantly higher in patients with spinal stenosis than those with disc herniation (all, $\mathrm{p}<0.05$ ). However, the difference in serum levels of TGF $-\beta 1(p=0.464)$, TIMP $-1 \quad(p=0.146)$ and TIMP $-2(p=0.794)$ was not significant between the lumbar spinal stenosis and disc herniation patients.

Conclusions: Despite increased levels of TGF $-\beta 1$, TIMP -1 , and TIMP -2 in the ligamentum flavum of spinal stenosis patients compared to disc herniation patients, the serum levels of TGF- $\beta 1$, TIMP-1 and TIMP-2 were very similar in both groups. These results indicate that the role of TGF- $\beta 1$, TIMP -1 and TIMP -2 on hypertrophy of the ligamentum flavum in spinal stenosis patients is a local phenomenon, not systemic.

Key Words: Spinal stenosis, Hypertrophy of ligamentum flavum, TGF- $\beta 1$, TIMPs, Local phenomenon

\section{Introduction}

Hypertrophy of the ligamentum flavum is one characteristic of degenerative lumbar spinal stenosis, which can cause neurogenic claudication secondary to compression of the cauda equina or nerve roots. Degenerative changes secondary to the aging process and mechanical stress such as instability have been reported to be attributed to hypertro- phy of the ligamentum flavum of lumbar spinal stenosis ${ }^{1-5}$. The authors of this study previously reported ${ }^{6,7}$ on what was thought to be the first' biochemical studies showing increased concentrations of transforming growth factor-beta 1 (TGF- $\beta 1$ ), tissue inhibitor of matrix metalloproteinase-1 (TIMP-1) and TIMP-2 in hypertrophied ligamentum flavum of patients with lumbar spinal stenosis compared to patients with lumbar disc herniation. Additionally, TGF- $\beta 1$, TIMP-1 and TIMP-2 were positively stained on fibroblasts of the

Corresponding author: Jong-Beom Park, MD

Department of Orthopedic Surgery, Uijongbu St. Mary's Hospital, The Catholic University of Korea

65-1 Kumho-dong, Uijongbu, Kyunggi-do, 480-717, Korea

Tel: +82-31-820-3578, Fax: +82-31-847-3671, E-mail: spinepjb@catholic.ac.kr 
ligamentum flavum, indicating that these proteins are synthesized by these cells. One issue that remained at the completion of the original two studies was the systemic implications of these proteins. We believe that it would be important to determine whether increased concentrations of TGF$\beta 1$, TIMP- 1 and TIMP- 2 in patients with spinal stenosis is a local or systemic phenomena. The purpose of the current study was to compare the serum levels of TGF- $\beta 1$, TIMP-1 and TIMP- 2 between patients with lumbar spinal stenosis and those with disc herniation.

\section{Materials and Methods}

Sixteen patients who had undergone decompressive surgery for neurogenic claudication due to single level lumbar spinal stenosis were included in this study. Twelve patients were female and four were male. The mean age of the patients was 60.2 years (range, 41 75 years) and the mean duration of symptoms between onset and operation was 14.7 weeks (range, 1 23 weeks). The operated levels were 10 at L4-L5, 5 at L5-S1, and 1 at level L3-L4. Patients with degenerative spondylolisthesis were excluded from the study. As control, sixteen patients who had undergone posterior open discectomy for radiating pain due to single level lumbar disc herniation were selected for this study. Ten patients were male and six were female. The mean age of the patients in this group was 32.4 years (range, 21 42 years), which was significantly younger than that of the patients with spinal stenosis $(\mathrm{p}<0.001)$. Patients with a history of diabetes mellitus, pulmonary disease, cardiovascular disease, and renal disease were excluded from this study.

\section{Measurement of ligamentum flavum thickness}

For each patient, an axial T1-weighted magnetic resonance image (repetition time, $600 \mathrm{msec}$; echo time, 30 msec) was obtained at the facet joint level of the lesion using a 1.5-tesler unit (Siemens, Somatoplus, Germany). The maximum thickness of the ligamentum flavum was traced using the manual cursor technique and computed automatically by the installed software in the magnetic resonance imaging scan. All of the radiographic analyses were independently performed by two experienced spine surgeons who were uninvolved in the patients' care. Each observer independently measured the thickness of the ligamentum flavum two times and the average of the four measurements was used as the final thickness.

\section{Extraction and quantification of protein from liga- mentum flavum}

Thirty-two ligamentum flavum specimens were obtained from all patients. A total of $100 \mathrm{mg}$ of the ligamentum flavum tissue was homogenized with phosphate-buffered saline at 3,000 rpm (Tissue Tearor/Biospec products, Racine, WI/model 985-370). Then centrifugation was performed with $15,000 \mathrm{rpm}$ at $4^{\circ} \mathrm{C}$ for 30 minutes and supernatant was obtained. Quantification of protein was performed according to Bradford's method using a protein assay kit (Catalog no. 500-0006; Biorad, Hercules, CA, USA), and optical density was measured at $595 \mathrm{~nm}$ by spectrophotometer (Ultrospec 3000; Pharmacia Biotech, Cambridge, UK). Ligamentum flavum tissue extracts containing $100 \mu \mathrm{g}$ of protein were used for measurement of TGF- $\beta 1$, TIMP-1 and TIMP-2.

\section{Local levels of TGF- $\beta 1$, TIMP-1 and TIMP-2 by ELISA assay}

Ligamentum flavum tissue extracts containing $100 \mu \mathrm{g}$ of protein were quantitatively analyzed for TGF- $\beta 1$, TIMP- 1 and TIMP-2 following the manufacturer's recommendations, using an enzyme-linked immunosorbent assay (ELISA) kit with antibodies that recognized human TGF- $\beta 1$, TIMP-1 and TIMP-2 (R \& D Systems, Minneapolis, MN, USA). For calibration we used human recombinant TGF- $\beta 1$, TIMP- 1 and TIMP-2 provided by the supplier to construct a standard curve and to obtain absolute values. TGF- $\beta 1$, TIMP-1 and TIMP-2 values were normalized to $100 \mu \mathrm{g}$ protein in each well.

\section{Serum levels of TGF- $\beta 1$, TIMP-1 and TIMP-2 by ELISA assay}

Following the manufacturer's instructions, ten cc of blood samples were obtained from the patients. Then serum was separated by centrifugation at 3,000 rpm for 15 minutes. TGF- $\beta 1$, TIMP- 1 and TIMP- 2 concentrations were measured twice for each sample using an ELISA kit with antibodies that recognized human TGF- $\beta 1$, TIMP-1 and TIMP2 (R \& D Systems). The average of the two measurements was used as the final concentration. For calibration, we used human recombinant TGF- $\beta 1$, TIMP- 1 and TIMP- 2 provided by the supplier to construct a standard curve and to obtain absolute values. 


\section{Statistical analysis}

An independent sample T-test was used to investigate the difference in patients' age, ligamentum flavum thickness, local and serum levels of TGF- $\beta 1$, TIMP- 1 and TIMP-2 between the lumbar spinal stenosis and disc herniation patients. A p value of less than 0.05 was considered statistically significant.

\section{Results}

\section{Thickness of ligamentum flavum}

The mean thickness of the ligamentum flavum was 5.34 $\pm 0.97 \mathrm{~mm}$ in patients with lumbar spinal stenosis and 2.54 $\pm 0.32 \mathrm{~mm}$ in patients with lumbar disc herniations. The difference was significant $(\mathrm{p}=0.001)$.

\section{Local levels of TGF- $\beta 1$, TIMP-1 and TIMP-2}

The mean concentration of TGF- $\beta 1$ in the ligamentum flavum was $127.43 \pm 53.62 \mathrm{pg} / \mathrm{mL}$ in the lumbar stenosis patients and $39.21 \pm 14.27 \mathrm{pg} / \mathrm{mL}$ in the herniation patients $(\mathrm{p}<0.05)$. The mean concentration of TIMP-1 in the ligamentum flavum was $7.92 \pm 2.35 \mathrm{ng} / \mathrm{mL}$ in the stenosis patients and $3.56 \pm 1.29 \mathrm{ng} / \mathrm{mL}$ in the herniation patients $(p<0.05)$. The mean concentration of TIMP-2 in the ligamentum flavum was $14.28 \pm 5.31 \mathrm{ng} / \mathrm{mL}$ in stenosis patients and $7.53 \pm 3.97 \mathrm{ng} / \mathrm{mL}$ in the herniation patients $(\mathrm{p}<0.05)$.

\section{Serum levels of TGF- $\beta 1$, TIMP-1 and TIMP-2}

The mean concentration of TGF- $\beta 1$ in serum was $32.84 \pm$ $16.37 \mathrm{pg} / \mathrm{mL}$ in the stenosis patients and $35.56 \pm 12.92$ $\mathrm{pg} / \mathrm{mL}$ in the herniation patients $(\mathrm{p}=0.464)$. The mean concentration of TIMP-1 in serum was $13.90 \pm 0.68 \mathrm{ng} / \mathrm{mL}$ in the stenosis and $13.94 \pm 0.93 \mathrm{ng} / \mathrm{mL}$ in the herniation patients $(\mathrm{p}=0.146)$. The mean concentration of TIMP- 2 in serum was $18.63 \pm 0.35 \mathrm{ng} / \mathrm{mL}$ in the stenosis patients and $18.92 \pm 0.38 \mathrm{ng} / \mathrm{mL}$ in the herniation patients $(\mathrm{p}=0.794)$.

\section{Discussion}

TGF- $\beta 1$ is known as a multifunctional cytokine involved in cellular proliferation, differentiation, and synthesis of extracellular matrix proteins ${ }^{8-14}$. It is also thought to play important roles in several physiological and pathological conditions such as wound repair, hypertrophic burn scars, and fibrotic disorders of the liver, kidney, heart, and lungs. TIMPs, inhibitors of MMPs, are believed to regulate the integrity and homeostasis of the extracellular matrix. Especially, increased expressions of TIMP-1 and TIMP-2 have been implicated in increased fibrosis of a wide variety of human organs, including the liver, kidney, lungs, and heart, by reduced MMPs activitie ${ }^{15-19}$. Decreased MMPs activities results in impairment of matrix degradation, which has been demonstrated to be associated with fibrotic diseases.

In previous studies ${ }^{6,7}$, the concentrations of TGF- $\beta 1$, TIMP-1 and TIMP-2 produced by fibroblasts might have been attributed to hypertrophy of the ligamentum flavum in patients with lumbar spinal stenosis via autocrine or paracrine fashions. However, there have been no studies to determine whether an increased concentration of TGF- $\beta 1$, TIMP-1 and TIMP-2 in patients with spinal stenosis is a local or systemic phenomena. We therefore undertook this study to compare the serum levels of TGF- $\beta 1$, TIMP- 1 and TIMP-2 between patients with lumbar spinal stenosis and disc herniation.

The thickness of the ligamentum flavum and the age of spinal stenosis patients were significantly higher compared to the disc herniation patients in this study. The local levels of TGF- $\beta 1$, TIMP-1 and TIMP-2 were significantly higher in the ligamentum flavum of patients with lumbar spinal stenosis than those with disc herniation. Furthermore, we found that serum levels of TGF- $\beta 1$, TIMP-1 and TIMP-2 were very similar in both groups with no significant difference. These results suggest that the role of TGF- $\beta 1$, TIMP-1 and TIMP-2 on hypertrophy of the ligamentum flavum in lumbar stenosis patients is not a systemic phenomenon but rather a local one. In addition, we excluded from the study patients with any history of diabetes mellitus, pulmonary disease, cardiovascular disease, and renal disease that could have affected the serum levels of these proteins. Therefore, serum levels of TGF- $\beta 1$, TIMP- 1 and TIMP- 2 measured in the current study can be used as normal values of these proteins in the serum. However, we should be cautious in interpreting these results because of the sex distribution differences between two groups.

\section{REFERENCES}

1. Beamer YB, Garner JT, Shelden CH: Hypertrophied lig- 
amentum flavum. AMA Arch Surg 1973; 106: 289-292.

2. Fukuyama S, Nakamura T, Ikeda T, Takagi K: The effect of mechanical stress on hypertrophy of the lumbar ligamentum flavum. J Spinal Disord 1995; 8: 126-130.

3. Schräder P, Grob D, Rahn BA, Cordey J, Dvorak J: Histology of the ligamentum flavum in patients with degenerative lumbar spinal stenosis. Eur Spine J 1999; 8: 323-328.

4. Yahia LH, Garzon S, Strykowski H, Rivard CH: Ultrastructure of the human interspinous ligament and ligamentum flavum. A preliminary study. Spine 1990; 15: 262-268.

5. Yoshida M, Shima K, Tangiguti Y, Tamaki T, Tanaka T: Hypertrophied ligamentum flavum in lumbar spinal canal stenosis. Pathogenesis and morphologic and immunohistochemical observation. Spine 1992; 17: 1353-1360.

6. Park JB, Chang H, Lee JK: Quantitative analysis of transforming growth factor-beta 1 in ligamentum flavum of lumbar spinal stenosis and disc herniation. Spine 2001; 26: E492-495.

7. Park JB, Lee JK, Park SJ, Riew KD: Hypertrophy of ligamentum flavum in lumbar spinal stenosis associated with increased proteinase inhibitor concentration. J Bone Joint Surg Am 2005; 87: 2750-2757.

8. Bollineni JS, Reddi AS: Transforming growth factor-beta 1 enhances glomerular collagen synthesis in diabetic rats. Diabetes 1993; 42: 1673-1677.

9. Li RK, Li G, Mickle DA, et al: Overexpression of transforming growth factor-beta 1 and insulin-like growth factor-1 in patients with idiopathic hypertrophic cardiomyopathy. Circulation 1997; 96: 874-881.

10. Nagy P, Schaff Z, Lapis K: Immunohistochemical detection of transforming growth factor- $\beta 1$ in fibrotic liver diseases. Hepatology 1991; 14: 269-273.

11. Roberts AB: Molecular and cell biology of TGF-beta.
Miner Electrolyte Metab 1998; 24: 111-119.

12. Schmid P, Itin P, Cherry G, Bi C, Cox DA: Enhanced expression of transforming growth factor- $\beta$,type I and type II receptors in wound granulation tissue and hypertrophuc scar. Am J Pathol 1998; 152: 485-493.

13. van Laethem JL, Robberecht $\mathbf{P}$, Resibois A, Deviere J: Transforming growth factor beta promotes development of fibrosis after repeated courses of acute pancreatitis in mice. Gastroenterology 1996; 110: 576-582.

14. Waltenberger J, Lundin L, Oberg K, et al: Involvement of transforming growth factor-beta in the formation of fibrotic lesions in carcinoid heart disease. Am J Pathol 1993; 142: 71-78.

15. Arthur MJ, Iredale JP, Mann DA: Tissue inhibitors of metalloproteinases: role in liver fibrosis and alcoholic liver disease. Alcohol Clin Exp Res 1999; 23: 940-943.

16. Bode W, Maskos K: Structural basis of matrix metalloproteinases and their physiological inhibitors, the tissue inhibitors of metalloproteinases. Biol Chem 2003; 384: 863-872.

17. Hayakawa T, Yamashita K, Tanzawa K, Uchijima E, Iawata K: Growth promoting activity of tissue inhibitor of metalloproteinases-1 (TIMP-1) for a wide range of cells. A possible new growth factor in serum. FEBS Lett 1992; 298: 29-32.

18. Kossakowska AE, Edwards DR, Lee SS, et al: Altered balance between matrix metalloproteinases and their inhibitors in experimental biliary fibrosis. Am J Pathol 1998; 153: 1895-1902.

19. Lichtinghagen R, Michels D, Haberkorn CI, et al: Matrix metalloproteinase (MMP)-2, MMP-7, and tissue inhibitor of metalloproteinase- 1 are closely related to the fibroproliferative process in the liver during chronic hepatitis C. J Hepatol 2001; 34: 239-247. 